\title{
EFEITO DO pH E DA HIDRÓLISE TRÍPTICA SOBRE AS PROPRIEDADES EMULSIONANTES DA GLOBINA BOVINA ${ }^{1}$
}

\author{
Cleia Batista Dias ORNELLAS², Janaína Guernica SILVA², \\ Marialice Pinto Coelho SILVESTRE ${ }^{2, *}$
}

\begin{abstract}
RESUMO
No intuito de estudar o efeito do pH e da ação da tripsina sobre as propriedades emulsionantes da globina bovina, extraída pelo método da acetona acidificada, foram determinados neste trabalho, a capacidade emulsionante (EC), o índice de atividade emulsionante (EAI) e a estabilidade da emulsão (ES). Testaram-se os valores de $\mathrm{pH}$ de 3,0 a 8,0 e os tempos de hidrólise de 5,0 a 60 min. Os dados obtidos indicam que os maiores valores de EC e ES foram obtidos no $\mathrm{pH} 5,0$ e 6,0, respectivamente, correspondente à faixa de alta solubilidade da proteína. Por outro lado, o EAI, além de apresentar um máximo no $\mathrm{pH} 3,0$, foi igualmente elevado nos valores de $\mathrm{pH} \mathrm{7,0} \mathrm{e} \mathrm{8,0,} \mathrm{situados} \mathrm{na}$ zona onde a globina é praticamente insolúvel. A hidrólise tríptica, nas condições empregadas, contribuiu para melhorar a EC, em toda a faixa de $\mathrm{pH}$ estudada, enquanto que para o EAI somente foi benéfico em pH 4,0 e 5,0. No caso da ES, este tratamento enzimático não foi vantajoso, promovendo melhoras apenas no pH 7,0, onde a proteína é insolúvel, e somente após 60 min de hidrólise.
\end{abstract}

Palavras-chave: sangue; globina bovina; hidrólise tríptica; propriedades emulsionantes

\begin{abstract}
SUMMARY
THE EFFECT OF THE PH AND THE TRYPTIC HYDROLYSIS ON THE EMULSIFYING PROPERTIES OF BOVINE GLOBIN.The effect of the $\mathrm{pH}$ and of the trypsin on the emulsifying properties of bovine globin, extracted by the acidified acetone method, was studied. The emulsifying capacity (EC), the emulsifying activity index (EAI) and the emulsion stability (ES) were determined at $\mathrm{pH}$ varying from 3.0 to 8.0 and employing hydrolysis times from 5 to $60 \mathrm{~min}$. The highest vaules for $\mathrm{EC}$ and $\mathrm{ES}$ were obtained at $\mathrm{pH}$ 5.0 and 6.0 , respectively, corresponding to the range of large protein solubility. On the other hand, the EAI was higher at $\mathrm{pH} 3.0$ and also at $\mathrm{pH} 7.0$ and 8.0, where the protein is insoluble. The tryptic hydrolysis produced an increase in $\mathrm{EC}$, in all $\mathrm{pH}$ ranges studied, while for the EAI the same effect was observed only in $\mathrm{pH} 4.0$ and 5.0 , and for $\mathrm{ES}$ at $\mathrm{pH} 7.0$ after 60 min of hydrolysis.
\end{abstract}

Keywords: blood, bovine globin, tryptic hydrolysis, emulsifying properties.

\section{1 - INTRODUÇÃO}

O sangue bovino, proveniente do abate em frigoríficos, é uma fonte potencial de proteínas de baixo custo, muito usada em diversos países na alimentação humana. Porém, no Brasil, somente uma pequena quantidade do sangue animal é utilizada para este fim [24,27].

${ }^{1}$ Recebido para publicação em 02/05/00. Aceito para publicação em 08/03/01.

${ }^{2}$ Departamento de Alimentos - Faculdade de Farmácia - UFMG. Av. Olegário Maciel, 2360/CEP : 31180-112 - Belo Horizonte, MG. Tel. (31)339-7633/FAX:339-7666. Email:malice@farmacia.ufmg.br ${ }^{*}$ A quem a correspondência deve ser enviada.
Em geral, as proteínas exibem propriedades funcionais de grande utilidade em produtos alimentares industrializados, entre elas a habilidade de agirem como emulsificantes. GOMEZ-JUAREZ et al [14] verificaram que a globina bovina apresentou boas propriedades funcionais, e, desta forma poderiam ser empregadas como substitutos de outras proteínas de custo elevado. Do ponto de vista industrial, a capacidade emulsionante apresenta grande interesse, uma vez que são inúmeros os alimentos (maioneses, patês, embutidos) cuja fabricação necessita do emprego de substâncias responsáveis por sua estabilidade. A ação de uma proteína como agente emulsionante é complexa e depende de fatores como a concentração protéica, tipo de óleo, velocidade e tempo de mistura, entre outros $[8,13,28]$. Além disso, as proteínas contribuem para enriquecer os alimentos do ponto de vista nutricional.

Segundo AUTIO et al [1] e O'RIODAN, MORRISSEY \& MULVIHILL [22], o fracionamento centrífugo do sangue produz plasma e um concentrado de células vermelhas. Freqüentemente, o plasma é adicionado a produtos cárneos, por apresentar uma formação de gel, principalmente após aquecimento. A fração de células vermelhas é pouco utilizada na alimentação devido a sua forte coloração e "flavor", apesar de conter $80 \%$ de toda proteína do sangue [21]. Contudo, alguns pesquisadores procuraram resolver este problema separando o grupo heme da globina, obtendo um produto claro e odor ameno, quando comparado à hemoglobina. Atualmente, é grande o número de estudos sobre as propriedades funcionais do plasma, em contraste com a outra fração.

A modificação da estrutura das proteínas, pela hidrólise enzimática, tem sido empregada no intuito de melhorar as propriedades funcionais, promovendo alteração do tamanho molecular, da conformação e das forças de ligação inter e intra moleculares [16]. O método mais comum consiste em promover uma hidrólise parcial empregando-se proteases altamente específicas, permitindo o controle do grau de hidrólise, e portanto, do tamanho dos peptídeos obtidos [3, 30].

O nosso grupo [10,11] verificou, anteriormente, que a hidrólise tríptica contribuiu para melhorar a EC da caseína em praticamente todos os valores de $\mathrm{pH}$ e tempos de reação estudados. Para o EAl, esse tratamento foi benéfico apenas na faixa de $\mathrm{pH}$ de 3,0 a 5,0 , enquanto a ES foi prejudicada em todos os valores de $\mathrm{pH}$ testados.

Este trabalho teve, portanto, como objetivo estudar o efeito do $\mathrm{pH}$ e da hidrólise tríptica sobre as pro- 
priedades emulsionantes da globina bovina, extraída pelo método da acetona acidificada.

\section{2 - MATERIAL E MÉTODOS}

\section{1 - Obtenção do sangue bovino e separação das células vermelhas}

Os animais foram abatidos em Frigorífico sob Inspeção Federal, sendo o sangue coletado diretamente da ferida de sangria em frascos já contendo quantidade necessária de anticoagulante $(2 \mathrm{~mL}$ de solução de EDTA a $10 \mathrm{~g} / 100 \mathrm{~mL}$ de sangue total). No momento da coleta, evitou-se o contato entre a vasilha coletora e a pele do animal.

Após liberado pela Inspeção Federal, o sangue foi imediatamente levado ao Laboratório de Bromatologia da Faculdade de Farmácia - UFMG, onde foi centrifugado (centrífuga Jouan, modelo Br4i) a 3000rpm por 15 min, para a separação das células vermelhas (hemácias), as quais foram armazenadas sob refrigeração até o momento da extração da globina bovina, o que durava no máximo $24 \mathrm{~h}$.

\section{2 - Extração da globina bovina}

As hemácias, obtidas como descrito no item 2.1, foram hemolisadas pela adição de água destilada na proporção de 1:1 e o pH, ajustado para 4,0 com ácido ascórbico $(2 \mathrm{~g} / 100 \mathrm{~mL})$. Posteriormente, o ar foi borbuIhado por uma hora, para oxidação da hemoglobina a colemeta-hemoglobina, sendo o grupo heme removido e a globina precipitada, pela adição de solução de acetona acidificada (com HCl, 99:1) na proporção de 1:4. Em seguida, filtrou-se em papel de filtro e a globina, retida no filtro, foi lavada com solução de éter:etanol (3:1) e armazenada, em porções de aproximadamente $100 \mathrm{~g}$, em frascos de vidro cobertos com papel de filtro, contendo vários orifícios pequenos. Após secagem por ventilação forçada à temperatura ambiente, as porções de globina foram tamisadas (24mesh), pesadas, transferidas para frascos de vidro e congeladas em freezer a $-18^{\circ} \mathrm{C}$, até o momento do uso. A globina, assim obtida, foi denominada de GT.

\section{3 - Hidrólise tríptica da globina bovina}

Para a hidrólise tríptica da proteína, foi utilizada a metodologia descrita por CHOBERT, BERTRAND-HARD \& NICOLAS [7], com algumas modificações. A globina foi solubilizada em tampão (fosfato dissódico a 0,02mol/ $\mathrm{L}$ e ácido cítrico a 0,01mol/L), $\mathrm{pH} 8,0$ em uma concentração de $0,1 \mathrm{~g} / 100 \mathrm{~mL}$. Posteriormente, foi adicionada a tripsina (de pâncreas bovino, tipo XIII, tratada com TPCK, Sigma Chemical Co); previamente solubilizada no mesmo tampão, de maneira a se obter uma relação enzima:substrato de $0,1 \%$. A mistura foi, então, mantida em banho-maria (Fanen, modelo $116 \mathrm{~b}$ ) a $37^{\circ} \mathrm{C}$ sob agitação, por intervalos de tempo variando entre 5,10 , 15,30 e 60 minutos, para obter os hidrolisados trípticos T1, T2, T3, T4 e T5, respectivamente. Em todos os ensaios, a reação enzimática foi interrompida, reduzindo- se o pH da solução para 2,0 com ácido clorídrico. Os hidrolisados, assim preparados, foram liofilizados (liofilizador, modelo L4KR, Edwards do Brasil) e mantidos em freezer a uma temperatura de $-18^{\circ} \mathrm{C}$, até o momento de utilização.

\section{4 - Preparo das amostras}

A globina e seus hidrolisados trípticos foram solubilizados em solução tampão (fosfato dissódico a 0,02mol/L e ácido cítrico a 0,01mol/L) pH 7,0, na concentração de $0,1 \mathrm{~g}$ de proteína para $100 \mathrm{~mL}$ de solução. Após $30 \mathrm{~min}$, em banho-maria a $35^{\circ} \mathrm{C}$, estas soluções foram centrifugadas a $6.500 \mathrm{~g}$ por $10 \mathrm{~min}$ e filtradas em papel de filtro (quantitativo faixa azul, Framex). Os filtrados assim obtidos foram utilizados, imediatamente, para as análises, ou então armazenados no freezer, a uma temperatura de $-18^{\circ} \mathrm{C}$, até o momento do uso.

\section{5 - Concentração protéica ótima}

Para estabelecer a concentração protéica a ser utilizada nos vários experimentos, foram preparadas soluções de globina bovina, cujas concentrações variaram de 0,025 a $3,0 \mathrm{~g}$ de proteína por $100 \mathrm{~mL}$ de solução, em tampão (fosfato dissódico a 0,02mol/L e ácido cítrico a 0,01mol/L), pH 7,0. Em cada caso, determinou-se a EC, de acordo com o método descrito a seguir. Posteriormente, traçou-se uma curva de EC em função da concentração protéica.

\section{6 - Capacidade emulsionante (EC)}

Para a determinação da capacidade emulsionante, foi utilizado o método descrito por VUILLEMARD et al [29], com as adaptações descritas pelo nosso grupo $[10,11]$. A EC foi calculada pela fórmula 1,

$\mathrm{EC}=\frac{\mathrm{OE}(\mathrm{g})-\mathrm{OB}(\mathrm{g})}{\text { proteína(mg) }}$

na qual $O E$ e $O B$ correspondem à quantidade de óleo emulsionado, respectivamente, pelas amostras e pelo branco (solução tampão sem agente emulsionante).

\section{7 - Índice de atividade emulsionante (EAI)}

Na determinação do EAl, a metodologia empregada foi baseada no trabalho de PEARCE \& KINSELLA [23], com as modificações feitas pelo nosso grupo [10, 11]. O EAI foi calculado pela fórmula 2, proposta por CAMERON et al [5],

$E A l=\frac{2 T}{(1-\theta) \times C}$

sendo T a turbidez; q a fração de óleo gasto para formar a emulsão $(0,25)$; e C a concentração inicial de proteína $(0,2 \mathrm{~g} / 100 \mathrm{~mL})$. Por sua vez, a turbidez foi calculada pela multiplicação de 2,303 pela absorbância (A) e pelo fator de diluição (100), sendo este produto dividido pelo caminho óptico das cubetas $(0,01 \mathrm{~m})$. 


\section{8 - Estabilidade da emulsão (ES)}

O método utilizado para a determinação da ES foi relatado por CHOBERT, BERTRAND-HARD \& NICOLAS [7] e adaptado pelo nosso grupo [10, 11]. O DEAI\% foi calculado pela fórmula 3 ,

$$
\Delta \mathrm{EA} \mid \%=\frac{\left(\mathrm{EAl}_{\text {max }}-\mathrm{EAl}_{\min }\right) \times 100}{\left.E \mathrm{AA}\right|_{\max }}
$$

na qual o $\mathrm{EAl}_{\max }$ é o maior valor obtido para as emulsões diluídas logo após sua formação e o $E A I_{\text {min }}$ é o menor valor de EAI obtido pelas alíquotas após o armazenamento por 24 horas ou pelas alíquotas após o aquecimento a $80^{\circ} \mathrm{C}$. Os valores de ES foram calculados pela fórmula 4 .

$$
\mathrm{ES}=\frac{1}{\Delta \mathrm{EA} \mid \%}
$$

\section{9 - Efeito do $\mathrm{pH}$}

Para estudar a influência do $\mathrm{pH}$ na solubilidade e nas propriedades emulsionantes, o pH das soluções de globina bovina e de seus hidrolisados trípticos, preparados como descrito no item 2.4, foi ajustado para 3,0; 4,$0 ; 5,0 ; 6,0$ e 8,0 , antes de se proceder o aquecimento, centrifugação e filtração.

\subsection{0 - Análise Estatística}

As determinações de concentração protéica ótima, proteína bruta, EC, EAl e ES foram realizadas em triplicata.

Para a determinação da concentração protéica ótima, foi feita a análise de variância, em delineamento inteiramente casualisado, para verificar a presença de efeitos significativos $(p<0,05)$ e, nestes casos foi aplicado o teste de Duncan para determinar as diferenças entre as médias [25].

Para as determinações do efeito do $\mathrm{pH}$ e do tempo de hidrólise sobre a EC, EAI e ES foi adotado o delineamento em parcelas subdivididas (no qual os tempos de hidrólise eram as parcelas e os diferentes valores de $\mathrm{pH}$, as sub-parcelas) e análises de variância para determinar a existência de efeitos significativos ou interações entre os efeitos $(p<0,05)$. O teste de Duncan foi utilizado para determinar diferenças entre as médias, para os efeitos que se mostraram significativos pelo teste de $\mathrm{F}$ [25].

\section{3 - RESULTADOS E DISCUSSÃO}

\section{1 - Concentração protéica ótima}

A capacidade emulsionante de vários agentes está relacionada à sua concentração. Além disto, no caso de proteínas, a concentração ótima (na qual se obtém a EC máxima) depende do tipo de proteína envolvida. Assim, esse estudo deve ser realizado para cada proteína especificamente [10, 11].
Os resultados desta determinação estão apresentados na Figura 1. Observa-se que o valor máximo de EC para a globina bovina situa-se nas concentrações de 0,1 e $0,2 \%$, decrescendo a partir daí até atingir o mínimo a $0,5 \%$. Assim, $0,1 \mathrm{~g} \%$ foi escolhida como sendo a concentração protéica a ser utilizada em todas as determinações neste trabalho. Na verdade, este valor, de acordo com PEARCE \& KINSELLA [23], refere-se à concentração mínima necessária para se obter resultados reprodutíveis na determinação de propriedades emulsionantes.

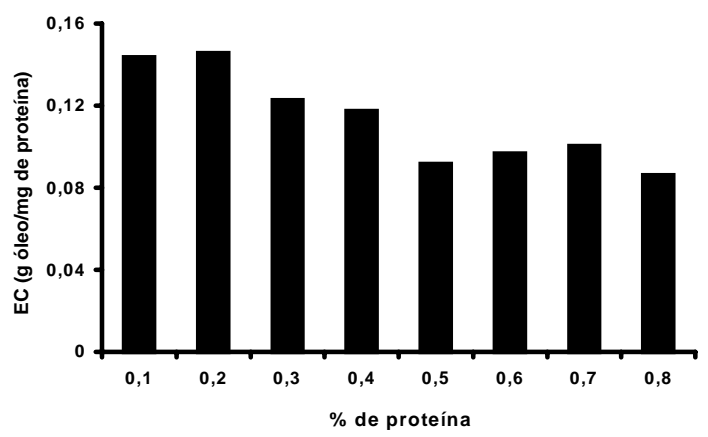

FIGURA 1. Variação da capacidade emulsionante em função da concentração de globina bovina. Os valores representam médias de três repetições.

CALDIRONI \& OCKERMAN [4], encontraram um EC máximo para a globina bovina GT, na concentração de $0,2 \mathrm{~g} \%$. Este estudo, entretanto, foi conduzido na presença de $\mathrm{NaCl}$ e $\circ \mathrm{pH}$ foi ajustado para 5,7 . CRENWELGE et al [8], após preparar uma solução aquosa de GT, obtiveram uma concentração ótima de $0,404 \mathrm{~g} \%$. Neste caso, porém, empregou-se um outro método para a determinação de EC, no qual a inversão da emulsão foi indicada pela queda repentina da viscosidade. Para a globina bovina, preparada por um método alternativo, também empregando acetona em associação com outros reagentes, SHAHIDI et al. [26] obtiveram um valor máximo de EC numa concentração de $0,5 \mathrm{~g} \%$ de proteína, em solução aquosa.

Em trabalho anteriormente publicado pelo nosso grupo [10], abordando o efeito da concentração protéica sobre a capacidade emulsionante da caseína, encontrou-se um valor máximo de EC equivalente ao obtido aqui para a GT $(0,1 \mathrm{~g} \%)$.

\section{2 - Efeito do pH e do tempo de hidrólise tríptica sobre a capacidade emulsionante}

Observa-se na Figura 2 um aumento da EC da globina bovina até atingir o máximo no $\mathrm{pH} 5,0$. Acima deste valor, a EC decaiu sendo que, no $\mathrm{pH}$ de 6,0 a 8,0, faixa onde essa proteína apresenta solubilidade mínima [17], a EC foi nula.

Segundo MANGINO [19], a EC mede a capacidade da proteína em migrar para a interface óleo-água e, para isto é necessário que a proteína seja suficientemente solúvel. Sabe-se que o pH tem um efeito sobre a carga da proteína influenciando desta maneira a sua solubilidade, sendo que no pl esta propriedade atinge o 
seu valor mínimo [6]. Conseqüentemente, em valores de $\mathrm{pH}$ próximos ao $\mathrm{pl}$ a proteína terá a sua capacidade de emulsificação altamente reduzida ou suprimida.

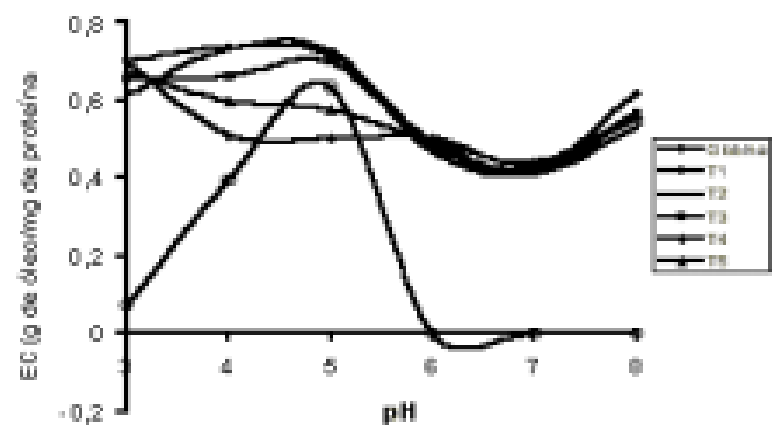

FIGURA 2. Efeito do pH e do tempo de hidrólise tríptica sobre a capacidade emulsionante da globina bovina. T1, T2, T3, T4 e T5 - hidrolisados de globina bovina obtidos aos 5, 10, 15, 30 e 60 min de reação. Os valores representam médias de três repetições.

Trabalhando igualmente com a globina GT, mas empregando um método diferente para medir a capacidade emulsionante (queda brusca da viscosidade), CRENWELGE et al [8] encontraram um máximo de EC para a GT, em solução aquosa, no pH 3,0, sendo que o valor mínimo foi verificado no $\mathrm{pH} 8,0$.

Nosso grupo mostrou, anteriormente, um comportamento diferente para a caseína. Assim, observou-se que, mesmo na faixa de $\mathrm{pH}$ onde sua solubilidade é mínima $(3,0$ a 5,0), esta proteína apresentou razoável capacidade emulsionante [10].

A hidrólise tríptica foi benéfica para a EC da globina bovina, principalmente na faixa de $\mathrm{pH}$ abaixo ou acima de 5,0, para todos os tempos de hidrólise estudados (Figura 2). Mesmo nesse valor de $\mathrm{pH}$, verifica-se que a hidrólise por até 15 min contribuiu para melhorar a EC desta proteína.

Segundo DAS \& KINSELLA [9], a hidrólise enzimática pode contribuir para aumentar a solubilidade de proteínas, uma vez que leva a uma maior exposição de grupos carregados, diminui o tamanho molecular, aumenta a hidrofilicidade, além de provocar alterações favoráveis na configuração molecular.

Com relação ao efeito da hidrólise sobre as propriedades emulsionantes, alguns autores afirmaram que, além da ação enzimática melhorar a solubilidade protéica, pode contribuir, ainda, para aumentar o número de pontos de contato entre a proteína e a interface óleo-água. Isto acontece, provavelmente, porque a hidrólise rompe a conformação nativa da proteína, expondo os grupos hidrofóbicos, que se tornam mais disponíveis para interagir com os lípides durante a formação da emulsão $[7,9,12,18]$. Uma melhora das propriedades emulsionantes das proteínas, geralmente é acompanhada pelo aumento do tempo de hidrólise. Por outro lado, uma forte ação enzimática pode ser prejudicial, devido à liberação de peptídeos não anfóteros, e à redução excessiva do tamanho da cadeia peptídica, tornando importante efetuar o controle do grau de hidrólise $(\mathrm{GH})$ da proteína. A obtenção de boas propriedades funcionais é alcançada para peptídeos contendo mais de 20 resíduos de aminoácidos [7, 12, 15].

Para a caseína, resultados obtidos pelo nosso grupo [10] indicam que a ação da hidrólise tríptica sobre a capacidade emulsionante, nas mesmas condições aqui empregadas, foi semelhante ao apresentado pela globina bovina, uma vez que este tratamento produziu um aumento da $\mathrm{EC}$ em todos os valores de $\mathrm{pH}$ estudados $(3,0$ a 8,0$)$.

\section{3 - Efeito do pH e do tempo de hidrólise tríptica sobre o índice de atividade emulsificante}

Como apresentado na Figura 3, a globina bovina apresentou valores de EAI variados em função do $\mathrm{pH}$, sendo máximos em pH 3,0, 7,0 e 8,0, ou seja, mesmo na faixa de $\mathrm{pH}$ onde se encontra o seu pl, ao contrário do observado para a EC.

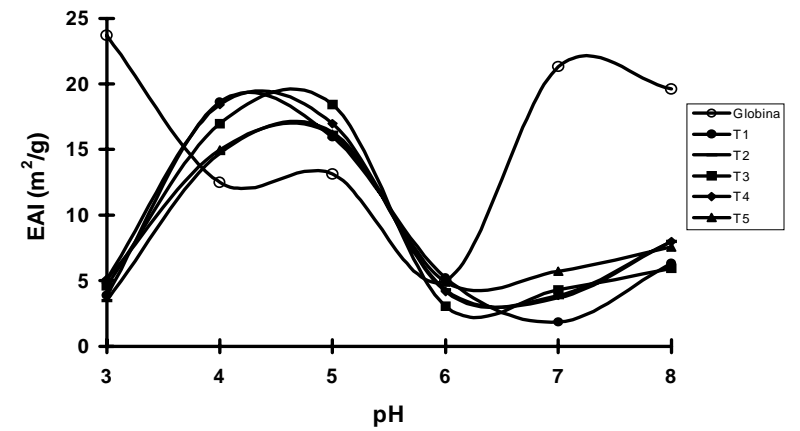

FIGURA 3. Efeito do pH e do tempo de hidrólise tríptica sobre o índice de atividade emulsionante da globina bovina. T1, T2, T3, T4 e T5 - hidrolisados de globina bovina aos 5, 10, 15, 30 e 60 min de reação. Os valores representam médias de três repetições.

Levando-se em conta que o EAI mede a capacidade da proteína em permanecer na interface óleo-água, logo após a formação da emulsão [19], a baixa solubilidade poderia, neste caso, dificultar a passagem da proteína para a fase aquosa, o que iria contribuir para a sua fixação nesta interface, elevando o valor de EAI.

Este mesmo tipo de comportamento foi mostrado pelo nosso grupo para a caseína, que apresentou um elevado valor de EAI, mesmo na faixa de $\mathrm{pH}$ de $3,0 \mathrm{a}$ 5,0 , quando sua solubilidade é praticamente nula [10].

A globina bovina, extraída por um método diferente do utilizado no presente estudo (emprego da carboximetilcelulose), apresentou uma curva distinta da que foi aqui obtida, a partir do $\mathrm{pH} 6,0$, tendo apresentado um valor mínimo de EAI no pH 7,0 [20]. Isto está de acordo com a afirmativa de AUTIO et al [2], de que as propriedades funcionais de proteínas não são determinadas apenas pela origem, mas também pelas condições de processamento.

No caso do EAI, a hidrólise tríptica da globina bovina somente produziu efeitos favoráveis em $\mathrm{pH} 4,0$ e 5,0 , inversamente do que foi obtido para a EC. 
A ação da tripsina sobre o EAl da caseína, igualmente ao obtido para a globina bovina, não produziu melhoras significativas, na maioria dos valores de $\mathrm{pH}$ estudados, como mostrado pelo nosso grupo [10]. Foi sobretudo na faixa ácida, que a hidrólise tríptica teve efeitos mais importantes, principalmente a partir de 10 minutos de reação.

\section{4 - Efeito do pH e do tempo de hidrólise tríptica sobre a estabilidade das emulsões}

Observa-se na Figura 4 que até o pH 5,0 a ES da globina bovina se manteve inalterada. Em seguida, houve um aumento acentuado, tendo atingido o máximo no $\mathrm{pH} 6,0$, próximo ao seu pl. A partir daí, verifica-se uma queda alcançando valores mínimos em pH 7,0 e 8,0, correspondente à faixa de menor solubilidade da proteína.

Quanto ao efeito do pH sobre a ES da caseína, nosso grupo obteve igualmente um valor elevado no $\mathrm{pH} 4,0$, próximo ao seu pl mas, o máximo foi atingido no $\mathrm{pH} 7,0$, onde a proteína é altamente solúvel [10].

A Figura 4 mostra, ainda, que a hidrólise tríptica pouco influenciou a ES da globina bovina. Apenas no $\mathrm{pH} 7,0$, ou seja no $\mathrm{pl}$ da proteína, e após 60 min de reação obteve-se uma melhora expressiva.

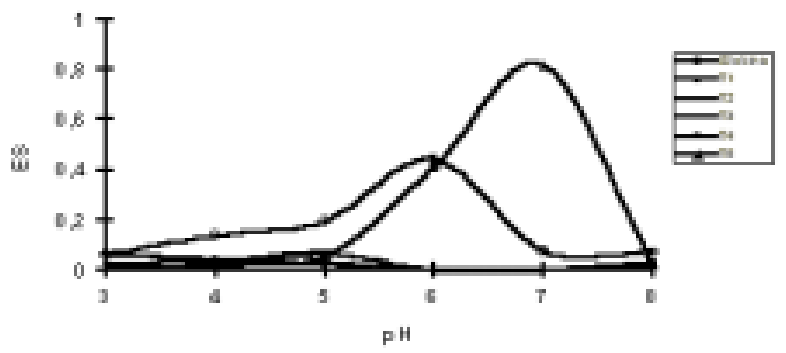

FIGURA 4. Efeito do pH e do tempo de hidrólise tríptica sobre a estabilidade da emulsão de globina bovina. $E S=1 / D E A I \% x$ 103. T1, T2, T3, T4 e T5 - hidrolisados de globina bovina obtidos aos 5, 10, 15, 30 e 60 min de reação. Os valores representam médias de três repetições.

No caso da caseína, o nosso grupo [10] mostrou que este tratamento não contribuiu para melhorar a ES em qualquer dos valores de $\mathrm{pH}$ estudados $(3,0$ a 8,0$)$.

$\mathrm{O}$ efeito do $\mathrm{pH}$ na estabilidade das emulsões apresenta uma certa complexidade. Assim, de acordo com MANGINO [19], em valores próximos ao pl, as proteínas são capazes de formar filmes interfaciais mais coesos e mais viscosos, o que é benéfico para a estabilidade da emulsão. Isto explicaria os resultados obtidos para a globina bovina.

DAS \& KINSELLA [9] relataram que os resultados obtidos por diferentes laboratórios, sobre o efeito do $\mathrm{pH}$ na estabilidade de emulsões, são contraditórios. Assim, existe um grupo que obteve o valor máximo de ES no pl, enquanto outros descreveram exatamente o oposto. Além da falta de padronização da metodologia empregada, sabe-se que a utilização de concentrações diferentes de proteínas nestes estudos, pode dar origem a filmes protéicos interfaciais possuindo propriedades e forças diversas.

A ação da hidrólise enzimática de proteínas na melhoria da estabilidade de emulsões está associada ao aumento da solubilidade e do GH [9, 12]. Isto foi, provavelmente, o que ocorreu com a globina bovina, que teve a sua ES aumentada pela ação da tripsina no $\mathrm{pH}$ correspondente ao seu pl.

Finalmente, ressalta-se o fato de que não foram encontrados na literatura relatos sobre o efeito da hidrólise tríptica sobre as propriedades emulsionantes da globina bovina.

\section{4 - CONCLUSÕES}

A influência do $\mathrm{pH}$ sobre as propriedades emulsionantes da globina bovina, extraída pelo método da acetona acidificada, mostrou que os melhores resultados (EC, ES e EAI) foram obtidos na faixa ácida de $\mathrm{pH}(3,0$ a 6,0$)$, na qual a proteína apresenta maior solubilidade. Para o EAl, acrescenta-se ainda valores elevados, mesmo na região na qual a proteína é praticamente insolúvel ( $\mathrm{pH} 7,0$ e 8,0). De um modo geral, pode-se dizer que a hidrólise tríptica foi vantajosa para estas propriedades, especialmente para a EC, em toda a faixa de $\mathrm{pH}$ estudada, e para o EAl, em pH 4,0 e 5,0. Por outro lado, foi necessário hidrolisar a proteína por 60 min, a fim de se obter uma melhora de sua ES apenas no $\mathrm{pH} 7,0$.

\section{5 - REFERÊNCIAS BIBLIOGRÁFICAS}

[1] AUTIO, K., LYYTIKÄINEN, H., MÄLKKI, Y., KANKO, S. Penetration studies of blood globin gels. J. Food Sci., v. 50, p. 615-617,1985.

[2] AUTIO, K., KIESVAARA, M., MÄLLKKI, Y., KANKO, S. Chemical and functional properties of blood globin prepared by a new method. J. Food Sci., v. 49, p. 859-862, 1984.

[3] BREKKE, C.J., SMITH, D.M., Enzymatic modification of the structure and functional properties of mechanically deboned fowl proteins. J. Agric. Food Chem., v. 33, p. 631-637, 1985.

[4] CALDIRONI, H.A., OCKERMAN, H.W. Incorporation of blood proteins into sausage. J. Food Sci., v.47, p. 405-407, 1982.

[5] CAMERON, D.R., WEBER, M.E., IDZIAK, E.S., NEUFELD, R.J., COOPER, D.G. Determination of interfacial areas in emulsions using turbidimetric and droplet size data: correction of the formula for emulsifying activity index. J. Agric. Food Chem., v. 39, p. 655-659, 1991.

[6] CHEFTEL, J.C., CUQ, J.L., LORIENT, D. Proteinas alimentarias; bioquímica, propiedades funcionales, valor nutritivo, modificações químicas. Zaragoza: Acribia, 1989.

[7] CHOBERT, J.M., BERTRAND-HARD, C., NICOLAS, M. G. Solubiliy and emulsifying properties of caseins and whey proteins modified enzimatically by trypsin. J. Agric. Food Chem., v. 36, p. 883 - 892, 1988.

[8] CRENWELGE, D.D., DILL, C.W., TYBOR, P.T., LANDMANN, W.A. A comparison of the emulsification capacities of some 
protein concentrates. J. Food Sci., v. 39, p. 175-177, 1974.

[9] DAS, K.P., KINSELLA, J.E. Stability of food emulsions: physicochemical role of protein and non protein emulsifiers. Adv. Food Nutr. Res., v. 34, p. 81-129, 1990.

[10] DUARTE, A.J., CARREIRA, R.L., JUNQUEIRA, R.G., COELHO, J.V., SILVESTRE, M.P.C. Propriedades emulsionantes e solubilidade da caseína bovina e de seus hidrolisados trípticos: 1 . Efeito do $\mathrm{pH}$ e do tempo de hidrólise. Ciênc. Tecnol. Aliment., v. 18, n. 3, p. 295-302, 1998a.

[11] DUARTE A.J., CARREIRA, R.L., JUNQUEIRA, R.G., COELHO, J.V., SILVESTRE, M.P.C. Propriedades emulsionantes e solubilidade da caseína bovina: 2 . Efeito da adição de $\mathrm{NaCl}$. Ciênc. Tecnol. Aliment., v. 18, n. 3 , p. 303-308, 1998b.

[12] GAUTHIER, S.F., PAQUIN, P., POULIOT, Y., TURGEON, $S$. Surface activity and related functional properties of peptides obtained from whey proteins. J. Dairy Sic., v. 76, p. 321-328, 1993.

[13] GILLETT, T. A., MEIBURG, D.E., BRONW, C.L., SIMON, S. Parameters affecting meat protein extraction and interpretation of model system data for meat emulsion formation. J. Food Sci., v. 49, p. 1606-1610, 1977.

[14] GOMEZ-JUAREZ, C.; CASTELLANOS, R.; PONCENOYOLA, T.; CALDERON-SALINAS, V.; FIGUEIROA, J. $D$. Functional properties of globin protein obtained from bovine blood by decolorisation of the red cell fraction. $\mathbf{J}$. Sci. Food Agric., v.79, n. 6, p.793-796, 1999.

[15] HAQUE, Z.U. Influence of milk peptides in determining the functionality of milk proteins: a review. J. Dairy Sci., v. 311-320, 1993.

[16] KINSELLA, J.E. Milk proteins: physicochemical and functional properties. Crit. Rev. Food Sci. Nutr., v. 21, p. 197-262, 1984

[17] KUPPEVELT, A.V., LEVIN, G., REIZENSTEIN, P. Small scale production and net protein utilization of globin. Globin fortification of cereals. Nutr. Rep. Inter., v. 13, n. 5, p. 429-443, 1976.

[18] MAHMOUND, M.I., MALONE, W.T., CORDLE, C.T. Enzymatic hydrolysis of casein: effect of degree of hydrolysis on antigenicity and physical properties. J. Food Sci., v. 57, p. 1223-1229, 1992.

[19] MANGINO, M.E. Protein interactions in emulsions: proteinlipid interactions. In: HETTIARACHCHY, N.S., ZIEGLER,
G.R. (Ed.) Protein functionality in food systems. New York: Marcel Dekker. 1994, Cap. 5, p.147-180.

[20] NAKAMURA, R., HAYAKAWA, S., YASUDA, K., SATO, Y. Emulsifying properties of bovine blood globin: a comparasion with some proteins and their improvement. J. Food Sci., v.49, p. 102-104, 1984.

[21] OCKERMAN, H. W.; HANSEN, C. L. Industrialización de subproductos de origem animal. Zaragoza: Acribia, 1994. P.244-263.

[22] O'RIODAN, D., MORRISSEY, P.A., MULVIHILL, D.M. Solubility characteristics of globin. Sci. Alim., v. 9, p. 455-461, 1989.

[23] PEARCE, K.N., KINSELLA, J.E. Emulsifying properties of proteins: evaluation of a turbidimetric technique. J. Agric. Food Chem., v. 26, n. 3, p. 716-723, 1978.

[24] PENTEADO, M.D.V.C., LAJOLO, F.M., SANTOS, N.P. Functional and nutritional properties of isolated bovine blood proteins. J. Food Sci. Agric., v. 30, p. 809-815, 1979.

[25] PIMENTEL-GOMES, F. Curso de estatística experimental. 9. ed. Piracicaba: Nobel, 1990.

[26] SHAHIDI, F., NACZK, M., RUBIN, L.J., DIOSADY, L.L. Functional properties of blood globin. J. Food Sci., v. 49, p. 370-372, 1984.

[27] SILVA, J. G.; ORNELLAS, C. B. D.; CARVALHO, M. G.; JUNQUEIRA, R. G.; OLIVEIRA, A. L.; SILVESTRE, M. P. C. Caracterização química e funcional do caseinato de sódio e da globina bovina. Ciênc. Tecnol. Aliment., v. 20, n. 2, p. 212-219, 2000.

[28] TYBOR, P.T., DILL, C.W., LANDMANN, W.A. Effect of descolorization and lactose incorporation on the emulsification capacity of spray-dried blood protein concentrates. J. Food Sci., v. 38, p. 4-6, 1973.

[29] VUILLEMARD, J.C., GAUTHIER, S.F., RICHARD, J.P., PAQUIN, P. Development of a method for measurement of the maximum value of emulsifying capacity of milk proteins. Milchwissenschaft, v. 45, n. 9, p. 572-575, 1990.

[30] WOOD, D.F. MA, C.Y. Functional properties of oat proteins modified by acylations, tripsin hydrolysis or linoleat treatment, JAOCS, v. 64, 1987.

\section{6 - AGRADECIMENTOS}

Os autores agradecem ao CNPq e à FAPEMIG pelo apoio financeiro. 